Pensamiento Crítico Vol.17. N¹1, pp. 79-92

\title{
La falacia de la estabilidad de precios
}

\author{
Pablo Rivas Santos
}

\section{RESUMEN}

El presente artículo evalúa la falacia de la estabilización de precios, estabilidad que anhelan las autoridades monetarias, quienes desean mantener el monopolio estatal de la emisión primaria. Los daños causados por la intervención estatal en los asuntos monetarios y los nefastos efectos causados por aquellas políticas monetarias que pretenden reducir la tasa de interés e incrementar la actividad del mercado mediante la expansión monetaria inorgánica generaron en la población el deseo de "estabilización". Se comprende la aparición de esta errónea idea y el atractivo que encierra para la gente al considerar las arbitrariedades padecidas por la moneda y el crédito.

Los precios de mercado son hechos históricos, resultado de una constelación de circunstancias registradas en cierto momento del irreversible proceso histórico. En el campo económico, el concepto de medición tiene poco sentido. En el mundo real de incesante cambio no hay puntos, objetos, cualidades o relaciones fijas que permitan medir las variaciones ocurridas.

El funcionamiento del cálculo económico solo necesita de un sistema monetario inmune a la ingerencia estatal. Cuando el BCR incrementa la cantidad de dinero para ampliar la capacidad adquisitiva del gobierno o bajar temporalmente la tasa de interés, desarticulan todas las relaciones monetarias y perturban el cálculo económico. El objetivo que persigue una sana política monetaria es impedir al gobernante hacer inflación e inducir la expansión crediticia de la banca privada. 


\section{Pensamiento Crítico Vol.I7. No I}

La idea de estabilizar el poder adquisitivo del dinero la generó el deseo de crear un mundo inmune al incesante fluir de las cosas de la gente, un mundo ajeno al continuo devenir histórico. Las rentas destinadas a atender perpetuamente las necesidades de fundaciones religiosas o instituciones de caridad; se reflejaron en esos terrenos, más tarde establecieron anualidades monetarias. Los donantes y beneficiarios suponían que las rentas representadas por una cierta cantidad de dinero no pueden ser afectadas por los cambios económicos; sin embargo, tales esperanzas resultaron fallidas. Las sucesivas generaciones pudieron comprobar cómo fracasaban los planes más cuidadosamente trazados por los difuntos empresarios. Golpeadas por dicha experiencia, la gente comenzó a razonar en torno a si habría alguna fórmula que permitiera alcanzar tan deseados objetivos. Por ello, los economistas se lanzaron a especular en torno a las variaciones del poder adquisitivo del dinero, pretendiendo hallar fórmulas que permitieran eliminar esas variaciones.

Palabras Claves: precios de mercado, ingerencia estatal, cálculo económico, fluctuación de los precios de mercado.

\section{ABSTRAC}

This article evaluates the fallacy of price stabilization, stability they crave the monetary authorities who wish to maintain the monopoly of the monetary base. Damage caused by government intervention in monetary affairs, and the harmful effects caused by those monetary policies that aim to: reduce interest rates and increased market activity through monetary expansion inorganic; made people want stabilization. It includes the development of this erroneous idea and the appeal it holds for people, if we consider the arbitrary suffered by the currency and credit.

Market prices are historical facts, the result of a constellation of circumstances recorded, at one point, the irreversible historical process. In the economic field, the concept of measurement has little meaning. In the real world of constant change there is no points, objects, qualities or relations fixed to measure the changes occurred.

The operation of economic calculation only needs a monetary system immune from state interference. When the $\mathrm{BCR}$ increases the amount of money to expand the purchasing power of government or temporarily lower the interest rate; disarticulate all relations disturb the monetary and 


\section{Pablo Rivas Santos}

economic calculation. The objective of a sound monetary policy is to prevent the ruling to induce inflation and credit expansion private banks.

The idea of stabilizing the purchasing power of money was generated by the desire to create: a world immune to the incessant flow of people's things, a world alien to continuous historical process. Income perpetually designed to meet the needs of religious foundations or charities, are reflected in these fields. Later established monetary annuities. Donors and recipients is assumed that das income for a certain amount of money can not be affected by economic changes. However, such hopes were unsuccessful. Successive generations were able to see how they failed most carefully laid plans for the deceased entrepreneurs. Battered by the experience, people began to think about whether there would be some formula that would achieve such desired objectives. So, economists took to speculate on changes in the purchasing power of money, trying to find formulas that allow to eliminate these variations.

Keywords: market prices, state interference, economic calculation, fluctuation of market prices.

\section{Introducción}

Los precios fluctúan continuamente debido a que las circunstancias que generan las fluctuaciones están en continua fluctuación. El valor que la gente atribuye al dinero y los bienes es fruto de una momentánea elección, cada instante futuro puede originar nuevas circunstancias y provocar distintas valoraciones. Sorprende el que los precios no fluctuaran en mayor grado.

La experiencia cotidiana ilustra la fluctuación de los precios del mercado y; sin embargo, la gente, cuando se enfrenta con los precios, pretende olvidar tal realidad. Al razonar en torno a la producción y el consumo, las operaciones de mercado y los precios, la gente supone contradictoriamente la rigidez de estos últimos. Opinando que lo normal y procedente es mantener aquellos precios registrados ayer; y critica toda fluctuación de los precios.

La integración de los mercados locales en los mercados del ámbito nacional, la extensión de las transacciones comerciales al área mundial y el haberse montado

\section{8|}




\section{Pensamiento Crítico Vol.17. No I}

el comercio para proporcionar un continuo suministro de bienes de consumo, ha minimizado la frecuencia e importancia de las fluctuaciones de precios. Todo nos enfrentamos diariamente con una infinidad de problemas que suscitan las continuas compraventas.

Es fácil comprender el motivo de quienes ven perjudicados sus intereses inmediatos por la variación de precios, se quejan afirmando que el precio anterior era más justo y normal, asegurando que la estabilidad de precios concuerda con las supremas leyes de la naturaleza y la moral. Toda variación de precios, al mismo tiempo que perjudica a unos, favorece a otros ${ }^{1}$.

\section{La falacia de la estabilización de precios}

Los daños causados por la intervención estatal en los asuntos monetarios y los nefastos efectos causados por aquellas políticas monetarias que pretenden reducir la tasa de interés e incrementar la actividad del mercado mediante la expansión monetaria inorgánica generó que la gente deseara la "estabilización". Se comprende la aparición de esta errónea idea y el atractivo que encierra para la gente; sí consideramos las arbitrariedades padecidas por la moneda y el crédito.

Esa "estabilidad" a la que aspiran las políticas monetarias es un concepto inútil y contradictorio. El deseo de actuar (el afán por mejorar nuestras condiciones de vida) es consustancial con la naturaleza humana. La gente continuamente cambia, cambiando

1 No opinarán los favorecidos lo mismo que aquellos perjudicados acerca de la supuesta condición equitativa y natural de la invariabilidad de precios. La popularidad de la idea de la estabilidad de precios solo viene a ser comprensible al advertir que se ha pretendido abordar las relaciones sociales con arreglo al sistema de las ciencias naturales. Los economistas que pretenden estructurar las Ciencias Económicas como si se tratara de las Ciencias Físicas inciden en los mismos erróneos cauces mentales que engendraron aquellas mencionadas equivocaciones tan populares y extendidas.

Incluso a esos economistas les falto imaginación para vencer esas falacias. Los economistas clásicos creían que el valor era un hecho objetivo; en su opinión constituía un fenómeno más del mundo externo, una condición inherente a las cosas, que, por tanto, podía ser ponderado y medido. No fueron capaces de advertir el carácter puramente humano y personal de los juicios de valor.

A la Economía le interesa refutar aquellas erróneas ideas según las cuales cabe alguna forma de medición en el mundo de la acción humana. Las desgraciadas medidas estabilizadoras que prevalecen fueron engendradas por aquel supuesto según el cual existe, en las relaciones interhumanas, fija correlación que puede ser cifrada y medida. 


\section{Pablo Rivas Santos}

al mismo tiempo sus valoraciones, deseos y actuaciones. En el mundo del actuar de las personas nada es permanente, solo el cambio lo es. En ese continuo fluctuar, sólo las categorías del razonamiento puro del actuar de la gente permanecen constantes. Es inútil pretender arrancar (de aquella inestabilidad típica del hombre y de su conducta) el preferir y el actuar; como si en el universo existieran valores eternos, independientes de los juicios de valor humano con respecto a los cuales cabría enjuiciar la efectiva actuación de las personas.

Las fórmulas propuestas para medir el poder adquisitivo del dinero descansan en el supuesto de imaginar que existe alguien en el mercado de condición permanente que puede determinar (sirviéndose de cierto patrón fijo) la cantidad de satisfacción proporcionada por cierta suma de dinero. Débil apoyo recibe tan inadmisible supuesto cuando se dice que lo que se pretende es ponderar solo la variación del poder adquisitivo del dinero; pues en ese concepto de la determinación del poder adquisitivo se basa la idea de la estabilización. El inexperto en un comienzo suponía que el dinero servía para medir los precios creía que las fluctuaciones en los tipos de intercambio solo se registraba en la diferente valoración de los bienes entre sí; permaneciendo constante el tipo de intercambio entre el dinero y la totalidad de los bienes. Después, la gente volvió la idea del revés, se negó la constancia del valor del dinero, afirmándose, en cambio, la constancia valorativa de la totalidad de los bienes que podían ser objeto de compraventa. Se ingeniaron diferentes conjuntos de productos, los cuales se contrastaban con la unidad monetaria. Existía tal deseo de encontrar índices (a cuyo amparo cabría medir el poder adquisitivo) que toda oposición fue derrotada. No se quiso tomar en cuenta la poca precisión de las estadísticas de precios manipuladas, ni en la imposibilidad -por su heterogeneidad- de comparar muchos de estos precios entre sí, ni en el carácter arbitrario de los sistemas seguidos para la determinación de cifras promedias.

Los partidarios de la estabilización contrastan el nuevo sol con aquella canasta donde el ama de casa reúne los productos que compra en el mercado. El poder adquisitivo del nuevo sol variaría en proporción inversa a la suma de dinero necesaria para comprar el contenido de la canasta familiar. De acuerdo con estas ideas, la política de estabilización aspira a que no varíe ese excesivo gasto monetario. Tal planteamiento solo sería admisible si el ama de casa y su imaginaria canasta fuesen constantes: si la canasta hubiera de contener siempre los mismos productos e idéntica cantidad de cada uno de ellos; y si fuera constante la utilidad que ese conjunto de bienes tuviera para la familia. En la vida real, ninguna de esas condiciones se cumple.

\section{3}




\section{Pensamiento Crítico Vol.I7. No I}

Las calidades de los bienes producidos y consumidos varían continuamente. Las grandes diferencias de precios que (en cierto momento) registran entre sí las distintas variedades de un mismo producto, evidencian la certeza de lo señalado. Se dice que un sazonador es idéntico a otro; $y$, sin embargo, tanto compradores como vendedores distinguen múltiples calidades y especies de sazonadores. Es útil comparar los precios pagados en distintas plazas o en distintas fechas por productos que se agrupan (desde el punto de vista de la estadística) bajo una misma denominación; si consta limitadamente que la calidad de esos productos es idéntica, con la única excepción de su diferente ubicación. Por calidad entendemos todas aquellas propiedades del bien que los efectivos o potenciales compradores toman en cuenta al actuar. El solo hecho de que hay diversas calidades de todos los bienes de consumo; echa por tierra uno de los fundamentales supuestos del método estadístico basado en los números índices. No empaña la verdad de lo expuesto el que un limitado número de bienes de capital metales y productos químicos que cabe describir mediante fórmulas- puede ser objeto de necesaria especificación en lo que se refiere a sus cualidades típicas. Porque toda medición del poder adquisitivo necesariamente habrá de tomar en cuenta los precios de todos los bienes de consumo. Pretender evitar el obstáculo acudiendo a los precios de los factores de producción resulta igualmente inútil, ya que, por fuerza, se falsearía el cálculo al computar varias veces las diversas fases de producción de un mismo bien de consumo. Limitar el estudio a un cierto grupo de predeterminados bienes resulta arbitrario y vicioso.

Pero, aún dejando de lado todos estos insalvables obstáculos; es inalcanzable el objetivo ambicionado, ya que cambia únicamente la calidad técnica de los diversos bienes, ni que continuamente aparezcan nuevos, al mismo tiempo que otros bienes dejan de producirse; lo importante es que también cambian las valoraciones personales, lo cual provoca cambios en la demanda y producción. Los supuestos en que se ampara esa doctrina de la medición; sólo se darían en un mundo poblado por hombres cuyas necesidades y estimaciones fueran inmutables únicamente si la gente valorara los bienes siempre del mismo modo, sería admisible suponer que las oscilaciones de los precios reflejan efectivos cambios en el poder adquisitivo del dinero

Debido a que no es posible conocer la cantidad total de dinero invertido en bienes de consumo, durante cierto período de tiempo; los cálculos estadísticos se apoyan en los precios pagados por los distintos bienes. Esta realidad suscita otros dos problemas

\section{4}




\section{Pablo Rivas Santos}

imposibles de solucionar. Primero, es necesario asignar a cada bien distinto un coeficiente de importancia porque sería inadmisible operar con precios de bienes diversos sin ponderar su respectiva importancia en la economía familiar. Sin embargo, tal orden siempre será arbitrario. Segundo, es necesario promediar los datos una vez recogidos y clasificados, pero hay muchas formas de promediar; existe la media aritmética, geométrica, y la mediana. Cada uno de estos sistemas brinda diferentes soluciones. No existe razón para preferir uno, considerándolo como el único procedente. La elección que fuere es siempre arbitraria.

Si las circunstancias humanas fueran inmutables; si la gente no hiciera más que repetir iguales actuaciones, por ser su malestar siempre el mismo e idénticas las formas de remediarlo, o si fuera posible admitir que todo cambio acontecido en ciertos individuos o grupos (en lo que atañe a las anteriores cuestiones) viniera a ser compensado por contrapuesto cambio en otros individuos o grupos, de tal suerte que la total demanda y oferta no resultara afectada; ello supondría que nuestro mundo gozaba de plena estabilidad. En tal supuesto, no cabe pensar en una posible variación del poder adquisitivo del dinero. Los cambios en el poder adquisitivo del dinero afectan, en diferente grado y momento, a los precios de todos los bienes; siendo ello así, dichos cambios provocarán variaciones en la oferta y demanda, en la producción y el consumo. Por tanto, es inadmisible aquella idea implícita al hablar del nivel de precios, según la cual -manteniendo constante las restantes circunstancias- estos precios pueden subir o bajar de manera uniforme, porque dadas las demás circunstancias, si varía el poder adquisitivo del dinero, los precios jamás permanecen constantes.

En el campo económico no tiene sentido la idea de la medición. En el mundo cambiante, no hay ningún punto fijo, ninguna relación; en que pueda basarse la medición. El poder adquisitivo del dinero nunca varía de modo uniforme con respecto a todos aquellos bienes que pueden ser objeto de compraventa. Las ideas de estabilidad y estabilización no tiene sentido si no es relacionándolas con una situación estática, pero ni siquiera mentalmente es posible llegar a contemplar las últimas consecuencias lógicas de tal inmovilismo, que menos aún puede ser llevado a la práctica. Donde hay acción hay cambio; la acción es permanente causa de cambio.

Es inútil el redundante aparato con que el INEI pretende calcular los índices expresivos del poder adquisitivo de dinero y la variación del costo de vida. Estos

\section{5}




\section{Pensamiento Crítico Vol.17. No I}

números índices son torpe e impreciso reflejo de cambios que ya sucedieron. Cuando hay inflación, cuando los precios registran profundos cambios; esos índices nos proporcionan una tosca caricatura de realidades bien conocidas y constatadas a diario por todo el mundo. Cualquier ama de casa sabe más de las variaciones experimentadas por aquellos precios que le afectan, que cuantos promedios estadísticos cabe arbitrar. De poco le sirven a la ama de casa unos cálculos que nada le dicen ni de la calidad ni de la cantidad del bien que es posible comprar, al precio de la estadística. Cuando el ama de casa, para su personal información, procede a medir los cambios del mercado, fijándose solo del precio de dos o tres bienes, no está siendo ni menos científica ni más arbitraria que los estadísticos (que entre varios sistemas, se acogen a un sistema para computar las realidades del mercado) ${ }^{2}$.

El actuar de la gente provoca cambios, en cuanto se efectuará el actuar, la estabilidad quiebra, produciéndose cambios continuos. La historia es una secuencia de variaciones ${ }^{3}$, es inherente a la naturaleza humana: pretender mejorar las propias condiciones de vida; concebir nuevas ideas y ordenar la acción a tenor de las nuevas ideas.

Los precios de mercado son hechos históricos, resultado de una constelación de circunstancias registradas, en cierto momento, del irreversible proceso histórico. En el campo económico, el concepto de medición tiene poco sentido ${ }^{4}$, en el mundo real de incesante cambio no hay puntos, objetos, cualidades o relaciones fijas que permitan medir las variaciones ocurridas.

2 Nadie se deja engañar por los números índices. Nadie se atiene a la ficción de suponer que implican auténticas mediciones. Cuando se trata de cantidades que efectivamente pueden ser objeto de medida, no hay dudas ni desacuerdos en torno a las cifras resultantes. Realizadas las oportunas operaciones, tales asuntos quedan definitivamente zanjados. Nadie discute los datos referentes a la temperatura, la humedad, la presión atmosférica y demás cálculos meteorológicos. Solo damos por bueno un número índice; cuando suponemos que el número índice que la gente crea en su certeza; beneficia nuestros intereses. Mediante números índices no es posible resolver ningún dilema; tales datos estadísticos solo sirven para hacer irreconciliables los respectivos intereses.

3 El hombre no puede detener el curso de la historia creando un mundo totalmente estable, donde la propia historia resultaría inadmisible.

4 Pero en una imaginaria - e irrealizable- situación plenamente rígida y estable no hay cambio que pueda ser objeto de medida. 


\section{Pablo Rivas Santos}

\section{La base de la idea de la estabilización de precios}

El funcionamiento del cálculo económico solo necesita de un sistema monetario inmune a la ingerencia estatal ${ }^{5}$. Cuando el BCR incrementa la cantidad de dinero para ampliar la capacidad adquisitiva del gobierno o bajar temporalmente la tasa de interés, desarticulan todas las relaciones monetarias y perturban el cálculo económico. El objetivo que persigue una sana política monetaria es impedir al gobernante hacer inflación e inducir la expansión crediticia de la banca privada6.

La buena marcha del cálculo económico solo exige evitar que se produzcan graves y bruscas variaciones en la cantidad de dinero manejada por el mercado. Un patrón moneda sana cumple satisfactoriamente las condiciones necesarias para la correcta operación del cálculo económico, modifica mínimamente la relación entre la oferta y demanda de dinero; y consiguientemente es tan lenta la modificación de su poder adquisitivo; que los empresarios pueden despreciar en sus cálculos tales modificaciones sin temor a equivocarse. En el terreno del cálculo económico no es posible una precisión absoluta, aun excluyendo aquellos errores emanados de no tomar debidamente en consideración los cambios de las circunstancias monetarias. El empresario se ve obligado a manejar en sus planes datos referentes al futuro incierto; razona en torno a precios y costos futuros. La contabilidad y los libros diarios, cuando pretenden reflejar los resultados de pasadas actuaciones, tropiezan con los mismos problemas al valorar instalaciones, existencias y créditos contra terceros. Pese a tales inexactitudes, el cálculo económico alcanza su objetivo, ya que aquella incertidumbre es fruto de la secuela obligada del actuar que ha de abordar siempre un futuro desconocido.

La idea de estabilizar el poder adquisitivo del dinero la generó el deseo de crear un mundo inmune al incesante fluir de las cosas de la gente, un mundo ajeno al continuo devenir histórico. Las rentas destinadas a atender perpetuamente las necesidades de fundaciones religiosas o instituciones de caridad se reflejaron en esos terrenos. Más tarde establecieron anualidades monetarias. Los donantes y beneficiarios suponían que las rentas representadas por una cierta cantidad de dinero no pueden ser afectadas por

5 El cálculo económico no exige la estabilidad monetaria; al cálculo económico no le perturba el que no sea ni imaginable ni posible dotar al dinero de rígido e invariable poder adquisitivo.

6 Tales medidas de auténtico saneamiento monetario no guardan relación con aquellos planes confusos y contradictorios, orientados a estabilizar y congelar el poder adquisitivo del dinero. 


\section{Pensamiento Crítico Vol.I7. No I}

los cambios económicos, sin embargo, tales esperanzas resultaron fallidas. Las sucesivas generaciones pudieron comprobar cómo fracasaban los planes más cuidadosamente trazados por los difuntos empresarios. Golpeadas por dicha experiencia, la gente comenzó a razonar en torno a si habría alguna fórmula que permitiera alcanzar tan deseados objetivos. Por ello, los economistas se lanzaron a especular en torno a las variaciones del poder adquisitivo del dinero, pretendiendo hallar fórmulas que permitieran eliminar esas variaciones.

El asunto cobró particular importancia cuando los gobiernos comenzaron a emitir bonos de mediano y largo plazo, cuyo principal casi nunca habría de ser reembolsado. El Estado, esa eterna institución inmune a toda debilidad humana, brindaba oportunidad al ciudadano para que pusiera su riqueza a salvo de cualquier emergencia, ofreciéndole ingresos seguros y estables. Así se ingeniaban, sistemas que evitaban al individuo a tener, a diario, que arriesgar y reconquistar (en el mercado) rentas y riquezas. Quien invirtiera sus fondos en bonos emitido por el gobierno quedaría para siempre liberado de las insoslayables leyes del mercado y del yugo de la soberanía de los consumidores. Ya no habría de preocuparse por invertir su dinero en aquellos cometidos que sirvieran mejor los deseos y las necesidades de la gente. El poseedor de bonos del Estado se hallaba plenamente asegurado; ya cubierto de los peligros de la competencia del mercado (sancionadora de la ineficacia con graves pérdidas patrimoniales) la eterna institución estatal había acogido en su refugio, permitiéndole disfrutar tranquilamente de cuanto antes acumulara. Las rentas de tales favorecidos no dependían ya de haber sabido atender, del mejor modo posible, las necesidades de los consumidores; por el contrario, estaban plenamente garantizadas mediante impuestos recaudados gracias al Estado. Se trataba de gente que, en adelante, no tenían ya por qué servir a sus conciudadanos, sometiéndose a su soberanía; eran más bien socios del Estado, que gobernaba y exigía tributo a la gente. El interés pagado por el gobierno era inferior al interés que pagaba el mercado; sin embargo, tal perjuicio resultaba ampliamente compensado por la indiscutible solvencia del deudor, cuyos ingresos no dependían de haber sabido servir dócilmente al consumidor, sino que provenían de coactivos cobros fiscales.

Pese a los desagradables recuerdos que habían dejado los primeros préstamos al gobierno, la gente depositó amplia confianza en el gobierno, el que el gobierno daría fiel cumplimiento a las obligaciones que contrajera voluntariamente. Ahorristascapitalistas y empresarios advertían que en una economía de mercado la forma de 


\section{Pablo Rivas Santos}

conservar la riqueza acumulada era reconquistándola a diario en dura competencia con todos, con las empresas ya existentes y con aquellas empresas recién llegadas "que surgen de la nada". El empresario viejo y cansado, que no quería seguir arriesgando (en cometidos ingeniados para servir mejor al consumidor) las riquezas que un día ganó con esfuerzo; y los herederos de ajenas fortunas, indolentes y plenamente conscientes de su incapacidad preferían invertir sus fondos en bonos del Estado, buscando protección contra la implacable ley del mercado.

Sin embargo, la deuda pública perpetua e irredimible, supone plena estabilidad del poder adquisitivo del dinero el estado y su poderío podrá ser eterno, pero el interés pagado solo gozará de esa misma condición si es computado con arreglo a un patrón monetario de valor fijo. El inversionista que por tales caminos (buscando la seguridad) rehuye el mercado y la actuación empresarial; quien teme suscribir acciones y prefiere los bonos del Estado vuelve a encontrarse enfrentado con la misma realidad que tanto lo amedrentaba: con el problema del permanente cambio de todas las cosas humanas. Una vez más, constata que en el mercado la riqueza solo puede conquistarse a través de la propia mecánica del mercado; de suerte que es inútil ilusión en tal entorno pretender hallar inmarchitable fuente de riqueza.

\section{Conclusiones}

En la economía de mercado solo cabe adquirir y conservar la riqueza sirviendo acertadamente a los consumidores ${ }^{7}$. El gobierno puede imponer cargas tributarias a sus conciudadanos y tomar a préstamo el dinero de los conciudadanos. Ni el más despiadado gobernante logra, a la larga, violentar las leyes que rigen la vida y el actuar de la gente. Si el gobierno dedica las sumas tomadas a préstamo; aquellas inversiones a través de las cuales quedan mejor atendidas las necesidades de los consumidores; y (en libre y abierta competencia con los empresarios ) triunfa en tales cometidos, se hallará en la misma posición que cualquier empresario, es decir, podrá pagar rentas e intereses porque habrá cosechado una diferencia entre costos y rendimientos. Por el contrario, si el gobierno invierte desacertadamente dichos fondos, de tal suerte que no se produce el mencionado superávit, el capital correspondiente disminuirá e incluso desaparecerá, cegándose aquella única fuente que había de producir las cantidades necesarias para

$\overline{7}$ En el mundo no existe nada de cuanto suele denominarse estabilidad y seguridad, circunstancias estas que el esfuerzo humano nunca logrará imponer en el mundo. 


\section{Pensamiento Crítico Vol.17. No I}

el pago del principal e intereses. En tal supuesto solo cabe que el gobierno recurra al cobro fiscal, si es que desea dar fiel cumplimiento a lo que libremente pactara con quienes le prestaron su dinero. Mediante tales cargas tributarias penaliza a la gente por las sumas de dinero que el gobierno ayer dilapidó. El gobierno, como contrapartida de tal imposición, no presta ningún servicio a los ciudadanos y paga intereses por un capital que se ha consumido, que ya no existe. Sobre el tesoro público recae la pesada carga de torpes actuaciones anteriores.

Cabe justificar los préstamos al gobierno si son a corto plazo; en cambio, resultan inconsistentes los argumentos esgrimidos en favor de los préstamos de largo plazo para la guerra contra el narcoterrorismo. Cuanto exija el suministro del ejército, forzosamente habrá de ser obtenido restringiendo el consumo civil, trabajando más e incluso, consumiendo una parte del capital existente. La carga bélica recae íntegramente sobre la generación en lucha; a las subsiguientes generaciones les afecta el conflicto tan solo por cuanto heredaron menos de lo que, en otro caso, les hubiera correspondido. El financiar la guerra mediante la emisión de bonos públicos jamás supone transferir parte de la carga a los hijos o a los nietos de los combatientes, tal fórmula financiera constituye el sistema que permite repartir la carga del conflicto entre los ciudadanos, porque si el gasto bélico hubiera de ser atendido solo con impuestos, contribuirían al gasto bélico únicamente quienes dispusieran de fondos líquidos. Los demás no harían las adecuadas aportaciones, sirviéndose de los préstamos a corto plazo cabe minimizar dicha desigualdad, ya que hacen posible un oportuno repartimiento entre los propietarios de capital fijo.

El préstamo público a largo plazo supone una anómala institución en el marco de la economía de mercado, el cual perturba el funcionamiento de la economía de mercado. Tal fórmula financiera fue ingeniada en inútil intento por olvidar la natural limitación de la acción humana y crear una zona de eterna seguridad, que no sería afectada por la típica transitoriedad $e$ inestabilidad de las cosas humanas. Presuntuosa y engreída es la idea de convenir préstamos perpetuos, concertar contratos eternos y estipular cláusulas que el futuro más lejano haya de respetar. Poco interesa que los préstamos públicos sean o no emitidos formalmente con carácter perpetuo; implícitamente y en la práctica, se les considera de tal condición. En cierta época hubo gobiernos que efectivamente redimieron parte de la deuda pública mediante honrado reembolso de su principal. Sin embargo, lo cotidiano, siempre fue el ir acumulando nuevos débitos sobre los antiguos 


\section{Pablo Rivas Santos}

débitos. La historia financiera refleja un continuo y general incremento de la deuda pública, ya nadie supone que los gobiernos eternamente soportarán la pesada carga de los correspondientes intereses. Tarde o temprano, todas esas deudas, de una u otra forma, quedarán impagas ${ }^{8}$.

\section{Referencias bibliográficas}

Barro, Robert J. Macroeconomía. Alianza editorial. Segunda edición, 1990.

Friedman, Milton. Nueva reformulación de la teoría cuantitativa del dinero. Editorial Continental.

Friedman, Milton. Moneda y desarrollo. Editorial Ateneo.

Friedman, Milton. Teoría de Precios. Segunda Edición 1976.

Friedman, Milton. Reforma bancaria y programa de estabilización.

Friedman, Milton. Un Marco Teórico del análisis Monetario. CEMLA 1970.

Johnson, Harry. Ensayos de economía monetaria. Amorrurtu editores. Segunda Edición, 1970.

Kemmerer, Edwin Walter. El ABC de la inflación. BCRP.

Mundell Robert A. Teoría Monetaria. Ediciones Amorrurtu. Primera Edición, 1971.

8 No se puede considerar imperfección del cálculo económico el que sea inutilizable cuando se trata de abordar fantasiosos planes orientados a implantar impracticable régimen de absoluta quietud y eterna seguridad, inmune a las inevitables limitaciones de la acción humana. En el mundo, ningún valor es eterno, absoluto y no cambiante. Por eso, es inútil pretender hallar específicas medidas para tales valores. No se debe considerar imperfecto el cálculo económico por cuanto no concuerda con las arbitrarias ideas de quienes quisieran hallar perennes fuentes de renta, independientes de los procesos productivos humanos. Los desleales economistas se entusiasman por arbitrar justificaciones morales a tal actuar, pensando en la próxima renuncia de esos débitos abierta. 


\section{Pensamiento Crítico Vol.I7. No I}

Rothbard, Murray N. Moneda libre y controlada. Centro de estudios sobre la libertad.

Hayek, Friedrich. Desnacionalización del dinero, Instituto de Asuntos Económicos, Londres, 1978.

Mises, Ludwig. Reconstrucción monetaria. Centro de estudios sobre la libertad.

Mises, Ludwig. Teoría de la moneda y el crédito. Fundación Ignacio Villalonga.

Mises, Ludwig. Acción humana. Fundación Ignacio Villalonga. 